\title{
Lecithin/Sphingomyelin Ratios in Tracheal Aspirates from Newborn Infants
}

\author{
MARIO D'COSTA, ROGER DASSIN, AND HEATHER BRYAN \\ Departments of Clinical Biochemistry and Pediatrics, Mount Sinai Hospital and the University of Toronto, \\ Ontario, Canada
}

\begin{abstract}
A sensitive and rapid high-performance liquid chromatography method for determining lecithin/ sphingomyelin (L/S) ratios in small volume tracheal aspirates has been evaluated in 115 infants sampled within 3 h of delivery. Respiratory distress syndrome was present in 41 infants and all had $L / S$ ratios of $\leq 15$ (sensitivity $100 \%$ ). Respiratory distress syndrome was absent in 74 infants, 67 of whom had L/S ratios of $>15$ (specificity 91\%). Serial tracheal aspirates $(n=68)$ in 27 infants showed little change in nine respiratory distress syndrome infants with $L / S$ ratio $\leqslant \mathbf{1 5}$ over $3 \mathrm{~h}$ while 18 nonrespiratory distress syndrome infants with $L / S>15$ were more variable. In two infants initial immature ratios rose to maturity rapidly after birth. Comparison of amniotic fluid $\mathrm{L} / \mathrm{S}$ ratios obtained within $2 \mathrm{~h}$ of delivery correlated with the corresponding tracheal aspirate $\mathrm{L} / \mathrm{S}$ in 24 infants $(r=0.81, p<$ 0.001) although the latter were three times higher. This method may have potential routine application in the assessment of surfactant replacement and mechanical ventilator therapies. (Pediatr Res 22: 154-157, 1987)
\end{abstract}

\section{Abbreviations}

GA, gestational age

HPLC, high-performance liquid chromatography

L/S, lecithin/sphingomyelin

RDS, respiratory distress syndrome

TLC, thin-layer chromatography

PG, phosphatidylglycerol

Determining fetal pulmonary maturity by measuring $\mathrm{L} / \mathrm{S}$ ratios in amniotic fluid as an index of surfactant activity has been a standard practice in obstetrics for many years (1). The presence of an immature $\mathrm{L} / \mathrm{S}$ ratio in high risk pregnancies has influenced the timing of delivery in order to decrease the incidence of the RDS in the premature newborn infant. Replacement surfactant therapy for newborn infants with RDS has recently been introduced in several newborn centers and shown to ameliorate the severity of the course of the disease (2-6). This exciting new approach in treatment may rely on a clinical and radiological diagnosis of RDS (2-5), which can be imprecise, as not all prematurely born infants with respiratory symptoms have a primary pulmonary surfactant deficiency. Estimations of surfactant activity measured in tracheal fluid aspirated directly at or shortly after birth have been reported in human infants (6-10). The determination of $\mathrm{L} / \mathrm{S}$ ratios in these studies have been made by the TLC procedure on lipid extracts of fluid, a method commonly used for larger volumes of amniotic fluid. This

Received November 19, 1986; accepted February 25, 1987.

Dr. Mario D'Costa, Department of Clinical Biochemistry, Mount Sinai Hospital 600 University Avenue, Toronto, Ontario M5G 1X5, Canada. method is noted for its laborious and time-consuming aspects and for the many variable factors which can influence the ratio (11). In the human infant the amount of tracheal fluid normally available in single aspirations is usually quite small and therefore a sensitive procedure is desirable. We have developed and clinically validated a sensitive and rapid HPLC method for L/S ratios in amniotic fluid (12) and now report on its application to the measurement of $\mathrm{L} / \mathrm{S}$ ratios in tracheal fluid aspirates from newborn infants.

\section{MATERIALS AND METHODS}

Patients. Over an 18-method period tracheal fluid was aspirated from 115 newborn infants of high risk pregnancies during resuscitation at birth for the assessment of pulmonary maturity; GA ranged widely from 24 to $40 \mathrm{wk}$ and birth weights from 570 to $4050 \mathrm{~g}$. The numbers of babies related to GA groups and sex are listed in Table 1. Following resuscitation at delivery, chest radiographs determined the working clinical diagnosis for infants with clinical respiratory distress requiring intubation and assisted ventilation and for those needing only supplementary oxygen. RDS was diagnosed in 41 ventilated infants (GA 24 to $35 \mathrm{wk}$ ) based on x-ray presence of a diffuse reticular-granular pattern in the lung parenchyma and air bronchograms (Table 1); six of these infants died. Wet lung was noted in 19 infants (GA 24-34 wk) where chest radiographs showed normal lung aeration with increased perihilar markings and fluid in the fissures and 11 required mechanical ventilation (Table 1). Five infants were ventilated for other causes, three with focal pneumonias, one with pulmonary hypoplasia, and one with septicemia. Ten infants were ventilated for apnea of prematurity (GA $<30 \mathrm{wk}$, birth weight $<1420 \mathrm{~g}$ ). These babies had normal initial chest $\mathrm{x}-$ rays. A 32-wk infant who was ventilated for severe apnea died of herpes encephalitis at the age of 9 days (Table 1).

All samples were obtained within $3 \mathrm{~h}$ of delivery using no. 6 DeLee suction catheters (Argyle, St. Louis, MO) introduced either into the endotracheal tube in the intubated baby or directly below the cords into the trachea under direct vision laryngoscopy during resuscitation. In 27 of the intubated babies an additional 41 serial tracheal aspirates were obtained $(43 \%$ within the 1 st $h$ of life, $34 \%$ in the 2 nd h, and $16 \%$ in the $3 \mathrm{rd} \mathrm{h}$ ) in order to assess changes in tracheal fluid L/S with time after birth. Amniotic fluid, sampled within $2 \mathrm{~h}$ of delivery, was comapred with tracheal fluid obtained in 24 infants. Twenty $(83 \%)$ were amniocentesis samples obtained during Cesarian section deliveries while four were collected at the time of artificial rupture of the membranes within $2 \mathrm{~h}$ of delivery.

$L / S$ ratio determination. A new analytical procedure for the determination of $\mathrm{L} / \mathrm{S}$ in amniotic fluid has been described and is based on the separation of lecithin and sphingomyelin in Folch extracts of amniotic fluid by normal phase HPLC. This method has proved to be very sensitive, rapid and precise (12). A $10-\mu \mathrm{m}$ silica column (Waters microporasil $3.9 \times 30 \mathrm{~cm}$ ) was used with 
Table 1. Infant clinical data

\begin{tabular}{|c|c|c|c|c|c|c|c|c|c|}
\hline \multirow{2}{*}{$\begin{array}{c}\text { Gestation } \\
\text { (wk) }\end{array}$} & \multirow{2}{*}{$\begin{array}{c}\text { Birth wt } \\
\text { (kg, range) }\end{array}$} & \multicolumn{2}{|c|}{ Sex } & \multirow[b]{2}{*}{ Total } & \multicolumn{4}{|c|}{ Ventilated } & \multirow{2}{*}{$\begin{array}{c}\text { Not } \\
\text { ventilated }\end{array}$} \\
\hline & & $\mathrm{M}$ & $\mathrm{F}$ & & RDS & Wet lung & Other* & Apnea & \\
\hline $24-26$ & $0.57-1.06$ & 6 & 13 & 19 & 6 & 3 & 1 & 6 & 3 \\
\hline $27-29$ & $0.58-1.65$ & 22 & 14 & 36 & 18 & 4 & 2 & 4 & 8 \\
\hline $30-32$ & $0.93-2.19$ & 12 & 19 & 31 & 12 & 4 & 2 & 1 & 12 \\
\hline $33-35$ & $1.16-2.97$ & 8 & 13 & 21 & 5 & 0 & 0 & 0 & 16 \\
\hline $36-40$ & $2.32-4.05$ & 4 & 4 & 8 & 0 & 0 & 0 & 0 & 8 \\
\hline Total & & 52 & 63 & 115 & 41 & 11 & 5 & 11 & 47 \\
\hline
\end{tabular}

* pneumonia $(n=3)$, sepsis $(n=1)$, hypoplasia $(n=1)$.

a 3-cm silica guard column. The mobile phase was acetonitrile:methanol:water $(65: 21: 14)$. All solvents were reagent grade from Burdick and Jackson, Muskegon, MI. Chromatography was at ambient temperature with a flow rate of $1.9 \mathrm{ml} / \mathrm{min}$ and detection was by UV absorption at $205 \mathrm{~nm}$. Lecithin and sphingomyelin eluted with retention times of 5 to $6 \mathrm{~min}$ and 8 to 9 min, respectively (12), and $\mathrm{L} / \mathrm{S}$ ratios were computed with an online integrator (Hewlett-Packard 3390A). We used the same column manufacturer (Waters) in all our studies and observed no intercolumn variation. However, retention times and elution pattern may vary considerably with silica columns from other manufacturers. Details of the method precision (3-7\% CV) and recovery of phospholipids (77-85\%) have been described previously (12).

For the analysis of $\mathrm{L} / \mathrm{S}$ ratios in tracheal fluid the procedure has been modified as follows: tracheal fluid specimens were frozen at $-20^{\circ} \mathrm{C}$ immediately upon receipt in the laboratory and stored for batch analyses. Frozen samples were thawed just prior to analysis. The fluid in the suction catheters was rinsed out with $1.8 \mathrm{ml}$ of $0.9 \% \mathrm{NaCl}(\mathrm{w} / \mathrm{v})$ into glass centrifuge tubes. The amount of fluid normally collected was very small (rarely exceeding $100 \mu \mathrm{l}$ ), usually barely visible in the tubing and only rarely reaching the trap. The transfer of fluid from the catheters was facilitated by the use of a hemostat used to "milk" the saline/ sample through the catheter. Whenever it contained fluid the trap was also rinsed out with saline. The diluted specimen was mixed to homogeneity by thoroughly vortexing for $5 \mathrm{~min}$ and then centrifuged at $1000 \times g$ for 5 min to remove cells and debris. Clear supernatant $(1.5 \mathrm{ml})$ was extracted with $1.5 \mathrm{ml}$ of methanol and $3.0 \mathrm{ml}$ of chloroform by the procedure described previously (12). Blood and meconium-stained specimens were rejected. The final dried extract was redissolved in $50 \mu \mathrm{l}$ of methanol and $10 \mu \mathrm{l}$ were injected onto the column. Repeat injections (up to $40 \mu \mathrm{l}$ ) were made as required for samples containing low amounts of phospholipid.

\section{RESULTS}

Values for $\mathrm{L} / \mathrm{S}$ ratios measured in tracheal fluid aspirates obtained from 115 newborn infants ranged from 3 to over 100 (Fig. 1). Quantitation at levels $>100$ was not precise due to poor resolution of peaks as a result of the large lecithin peak overlapping with the sphingomyelin. At GA of 24 to $35 \mathrm{wk}$ the ratios ranged widely $(>3$ to $>100)$ whereas the ratios were all above 20 for babies in the GA range 36 to $40 \mathrm{wk}$ (Fig. 1). Forty-one ventilated infants were diagnosed clinically and radiologically as having RDS (Table 1) and all had L/S ratios of $\leqslant 15$ (Fig. 1). Seventy-four infants did not have radiological evidence of RDS (Table 1) and in 67 of these the $\mathrm{L} / \mathrm{S}$ ratios were $>15$ whereas in seven they were $\leqslant 15$ (Fig. 1). Three of these latter infants (GA 28,29 , and $34 \mathrm{wk}$ ) were diagnosed as having wet lung on chest $\mathrm{x}$-ray and the less mature infant required mechanical ventilation (Fig. 1). The other four infants had initial normal chest radiographs after birth (GA 27, 29, 33, and 34 wk), two of whom (GA 27 and 29 wk) were ventilated for apnea (Fig. 1). Of the 74

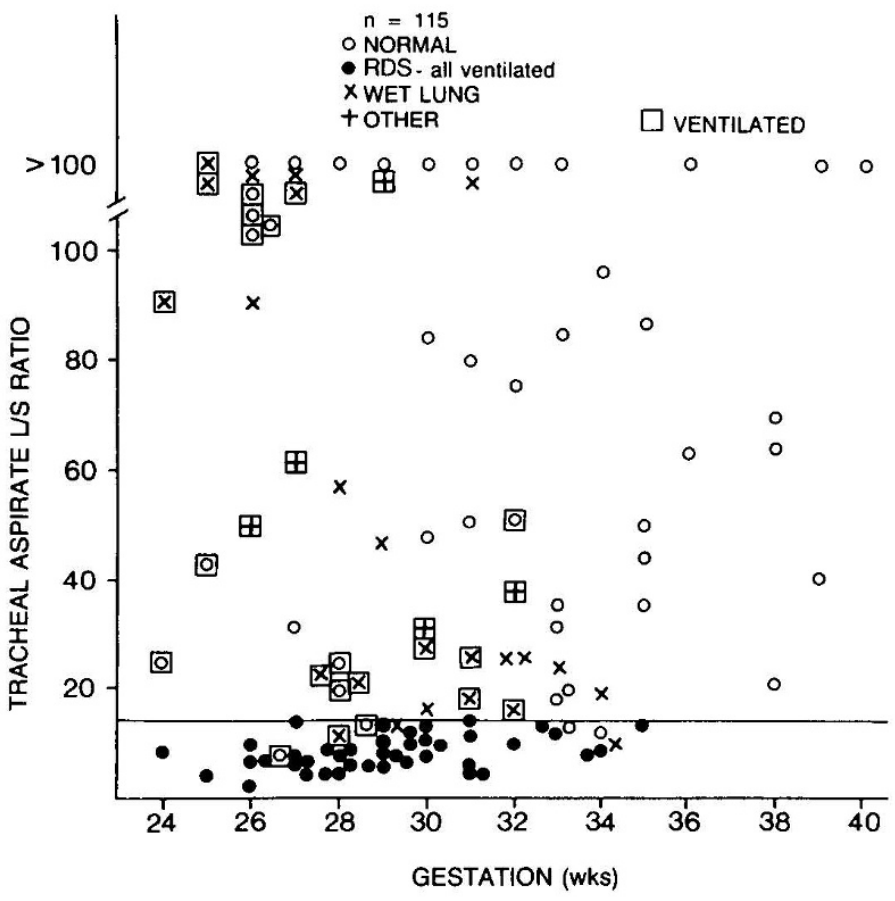

Fig. 1. Individual infant $\mathrm{L} / \mathrm{S}$ ratios measured in tracheal fluid aspirates within $3 \mathrm{~h}$ of delivery related to gestational age. Symbols represent the respiratory diagnosis and indicate the use of mechanical ventilation. All RDS babies were ventilated. Included are five infants represented as other + , three of whom had pneumonia, one septicemia, and one pulmonary hypoplasia. The horizontal line is the arbitrarily set limit of $\mathrm{L} / \mathrm{S}=15$. Ratios of $\leq 15$ indicate pulmonary immaturity.

Table 2. Relationship of tracheal fluid $L / S$ ratio with $R D S^{*}$

\begin{tabular}{lccc}
\hline & \multicolumn{3}{c}{ L/S ratio } \\
\cline { 2 - 4 } & $\leq 15$ & $>15$ & Total \\
\hline $\begin{array}{l}\text { RDS } \\
\text { Present }\end{array}$ & 41 & 0 & 41 \\
$\begin{array}{l}\text { RDS } \\
\text { Absent }\end{array}$ & 7 & 67 & 74 \\
\hline
\end{tabular}

${ }^{*}$ Sensitivity $=41 / 41 \times 100=100 \%$, specificity $=67 / 74 \times 100=$ $91 \%$.

infants who did not have RDS, 27 required assisted mechanical ventilation for wet lung in 11 , apnea of prematurity in 11 , and five for other causes (Table 1, Fig. 1).

From these results an arbitrary value for pulmonary maturity was set at an $\mathrm{L} / \mathrm{S}$ ratio of $>15$. The specificity (indicating absence of RDS) for these 115 infants was $91 \%(67 / 74)$ and the sensitivity (indicating the presence of RDS) was $100 \%(41 / 41)$ at $\mathrm{L} / \mathrm{S} \leqslant 15$ (Table 2). 


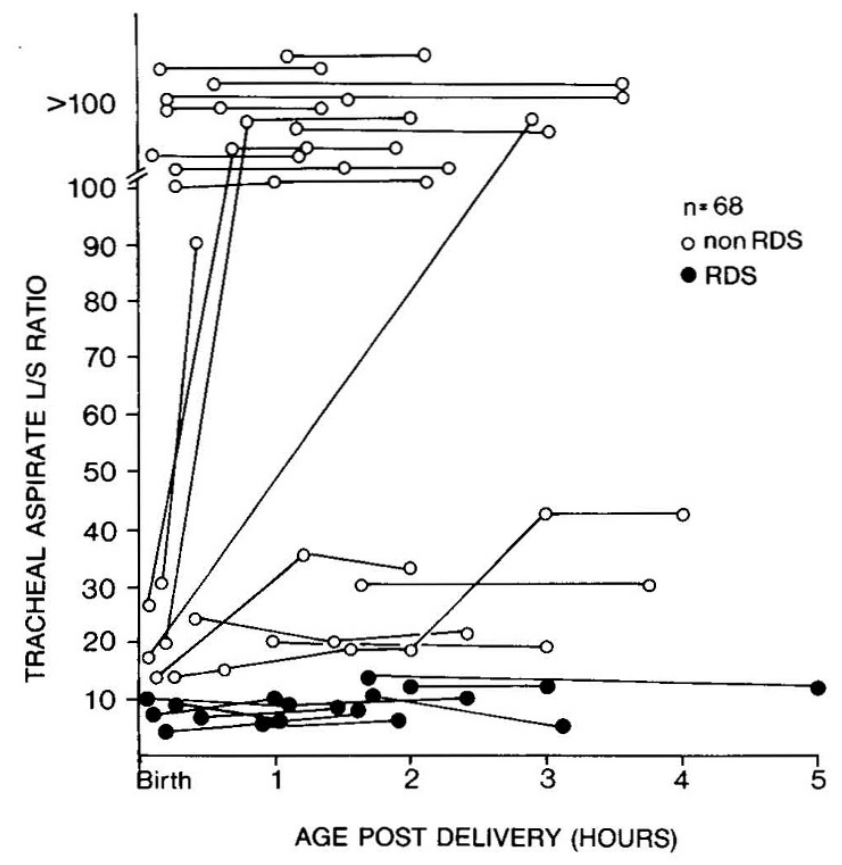

Fig. 2. Serial tracheal aspirate $\mathrm{L} / \mathrm{S}$ ratios $(n=68)$ obtained in 27 infants, nine of whom had RDS.

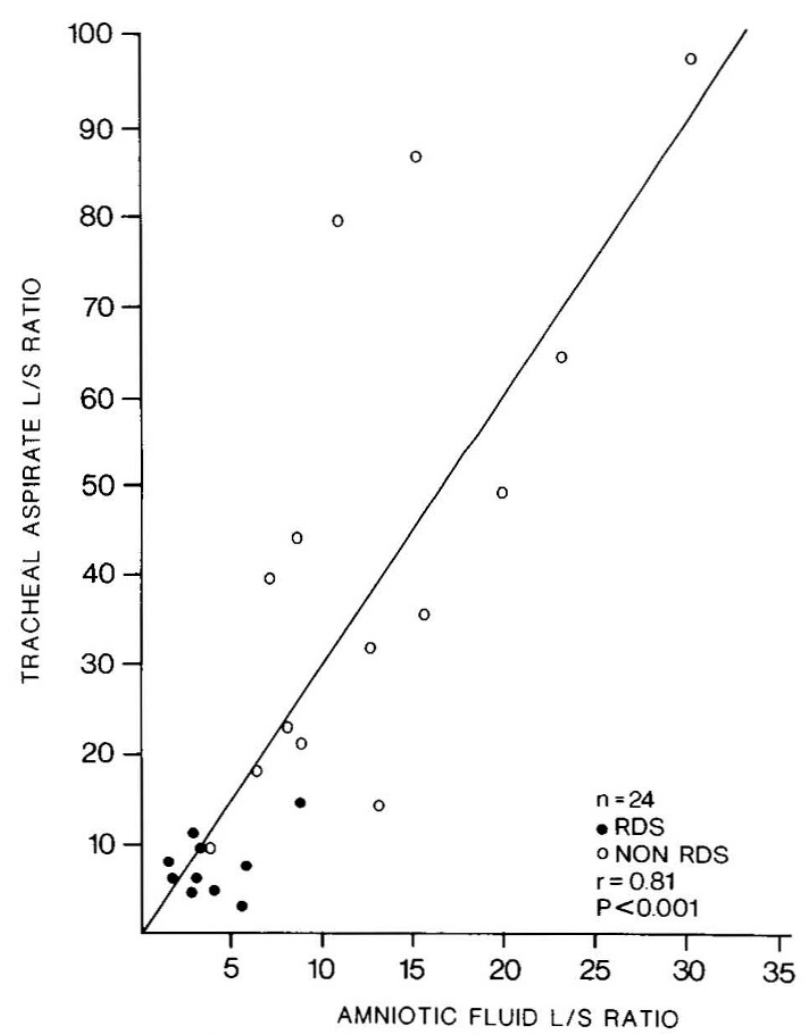

Fig. 3. The relationship of $\mathrm{L} / \mathrm{S}$ ratios in 24 amniotic fluid (obtained within $2 \mathrm{~h}$ of delivery) with the corresponding neonatal tracheal fluid (obtained within $3 \mathrm{~h}$ of birth). The slope of the regression line is 3.1 , intercept $=-0.1$.

Forty-one additional serial $\mathrm{L} / \mathrm{S}$ ratios were obtained in 27 infants, the majority by $3 \mathrm{~h}$ of age. In nine infants with RDS, the serial $\mathrm{L} / \mathrm{S}$ ratios were all immature $(\leqslant 15)$ and changed little with time after birth (Fig. 2). Of 18 non-RDS infants the L/S ratios were mature $(>15)$ in all but two. In these two infants the early $\mathrm{L} / \mathrm{S}$ ratios were immature, 13 and 14 respectively, obtained at 6 and $13 \mathrm{~min}$ of age. They rose to mature levels on subsequent sampling (Fig. 2). Large changes in ratios were seen in four of the non-RDS infants, two changed little after birth (Fig. 2) and those $>100$ could not be quantiated further. The range of GA was 24 to 39 wk with birth weights between 570 to $3240 \mathrm{~g}$.

Amniotic fluids obtained within $2 \mathrm{~h}$ of delivery during labor were measured for $\mathrm{L} / \mathrm{S}$ ratios and compared to tracheal fluid samples aspirated after birth in 24 infants (Fig. 3). Regression analysis showed a significant correlation $(r=0.81, p<0.001)$. Tracheal fluid L/S ratios were higher (approximately 3 times) than those obtained in the amniotic fluids. Ten infants in this group had clinical and radiological signs of RDS while 14 did not (Fig. 3). GA ranged from 26 to $39 \mathrm{wk}$ and birth weight 700 to $3470 \mathrm{~g}$.

\section{DISCUSSION}

We have described the application of a new HPLC method (12) for the measurement of $\mathrm{L} / \mathrm{S}$ ratios in small amounts of tracheal fluid obtained from neonates in the first $3 \mathrm{~h}$ of life. This method correctly predicted all 41 cases of RDS (100\% sensitive) with an arbitrarily selected limit of $\mathrm{L} / \mathrm{S}=\leqslant 15$. The procedure has some advantages over traditional TLC. Analyses failure because of sample insufficiency $(1,7)$ were few and pooling of serial tracheal fluid aspirates (9) was not necessary due to the high degree of sensitivity achieved with this HPLC method. Failures did occur when aspirates were contaminated with blood or meconium as with other methods. Quantitation was imprecise when measured L/S ratios were high $(>100)$ due to an overlapping lecithin peak, although these ratios were clearly mature. The HPLC method also has the advantage of being relatively fast. An individual determination performed by duplicate injections of the lipid extract can be achieved in under 30 min compared to 3 or 4 times as long by one or two dimensional TLC. It should be noted that PG cannot be fractionated by this system (12) and therefore cannot be measured simultaneously. As discussed extensively in our earlier report (12) UV detection monitors changes in both the unsaturated and saturated lecithins. However, it appears to do so with greater sensitivity and over a wider quantitative range than traditional TLC methods employing densitometric scanning.

Measuring L/S ratios soon after birth in tracheal fluid aspirates may be more direct than ratios measured either from gastric $(9$, 10) or hypopharyngeal fluids (7-9), because of the possible admixture and dilution effect from pharyngeal or swallowed amniotic fluid where the ratios are lower (Fig. 3). Higher phospholipid levels in tracheal aspirates compared to amniotic fluid have also been reported in full-term infants (13) and in fetal sheep (14).

Seven infants in this study who did not have radiological evidence of RDS had immature $\mathrm{L} / \mathrm{S}$ ratios $(\leqslant 15)$. Three were diagnosed as wet lung while four had normal chest radiographs. Mechanical ventilation was not needed in four of the seven (Fig. 1). Subsequent serial measurements in two of these infants indicated higher mature L/S ratios (Fig. 2). This lack of RDS in the presence of immature $\mathrm{L} / \mathrm{S}$ ratios has been reported by others using different methods $(7,9)$ and may reflect the fact that the movement of surfactant from the alveoli into the central airways is dependent on adequate alveolar ventilation (15). This may also explain the large and rapid increases seen with time in several non-RDS infants (Fig. 2). Our data suggest that a firm diagnosis of pulmonary maturity shortly after birth may be governed by the establishment of sustained and adequate infant respiration.

This sensitive and rapid HPLC method for determining L/S ratios in small volume tracheal aspirate samples taken shortly after birth has also been used successfully for similar measurements in amniotic fluids (12). This method has the potential of diagnosing a surfactant deficiency in early RDS and may be useful in the assessment of surfactant replacement and mechanical ventilator therapies. 
Acknowledgments. The authors thank the Medical and Nursing Staff of the Mount Sinai Neonatal Intensive Care Unit for their essential support which made this study possible and Julie Precious for typing the manuscript.

\section{REFERENCES}

1. Gluck L, Kulovich MV, Borer RC Jr, Brenner PH, Anderson GG, Spellacy WN 1971 Diagnosis of the respiratory distress syndrome by amniocentesis. Am J Obstet Gynecol 109:440-445

2. Fujiwara T, Maeta H, Chida S, Morita T, Watabe Y, Abe T 1980 Artificial surfactant therapy in hyaline-membrane disease. Lancet 1:55-59

3. Enhorning G, Shennan A, Possmayer F, Dunn M, Chen C, Milligan J 1985 Prevention of neonatal respiratory distress syndrome by tracheal instillation of surfactant: a randomized clinical trial. Pediatrics 76:145-153

4. Kwong MS, Egan EA, Notter RH, Shapiro SL 1985 Double-blind clinical trial of calf lung surfactant extract for the prevention of hyaline membrane disease in extremely premature infants. Pediatrics 76:585-592

5. Shapiro DL, Notter RH, Morin FC III, Deluga KS, Golub LM, Sinbin RA, Weiss KI, Cox C 1985 Double-blind, randomized trial of a calf lung surfactant extract administered at birth to very premature infants for prevention of respiratory distress syndrome. Pediatrics 76:593-599

6. Merritt AT, Hallman M, Bloom BT, Berry C, Benirschke K, Sahn D, Key T,
Edwards D, Jarvenpaa AL, Pohjavuori M, Kankaanpaa K, Kunnas M, Paatero H, Rapola J, Jaaskelainen J 1986 Prophylactic treatment of very premature infants with human surfactant. N Engl J Med 315:785-790

7. Weller PH, Jenkins PA, Gupta J, Baum JD 1976 Pharyngeal lecithin/sphingomyelin ratios in newborn infants. Lancet 1:12-15

8. Obladen M, Merritt TA, Gluck L 1979 Acceleration of pulmonary surfactant maturation in stressed pregnancies: a study of neonatal lung effluent. Am J Obstet Gynecol 135:1079-1085

9. Kankaanpaa K, Hallman M 1982 Respiratory distress syndrome in very low birth weight infants with occasionally normal surfactant phospholipids. Eur J Pediatr 139:31-34

10. James DK, Chiswick ML, Harkes A, Williams M, Hallworth J 1984 Nonspecificity of surfactant deficiency in neonatal respiratory disorders. Br Med J 288:1635-1638

11. Brown LM, Duck-Chong CG 1982 Methods of evaluating fetal lung maturity. CRC Crit Rev Clin Lab Sci 166:84-159

12. D'Costa M, Dassin R, Bryan MH, Joutsi P 1985 Validation of a simple rapid high performance liquid chromatography method for amniotic fluid lecithin/ sphingomyelin ratios. Clin Chem 18:27-31

13. Giudicelli Y, Pecquery R, Magyar C, Lacasa M, Nordmann R 1975 Studies on the phospholipids in tracheal aspirate from normal full term newborn infants. Comparison with amniotic fluid. Clin Chim Acta 60:335-346

14. Scarpelli EM 1967 The lung, tracheal fluid, and lipid metabolism of the fetus. Pediatrics 40:951-961

15. Faridy EE 1976 Effect of ventilation on movement of surfactant in airways. Respir Physiol 27:323-334 